\title{
Effective hemostasis with double-balloon rectal catheter for uncontrolled bleeding during endo- scopic mucosal resection of large rectal neoplasms
}

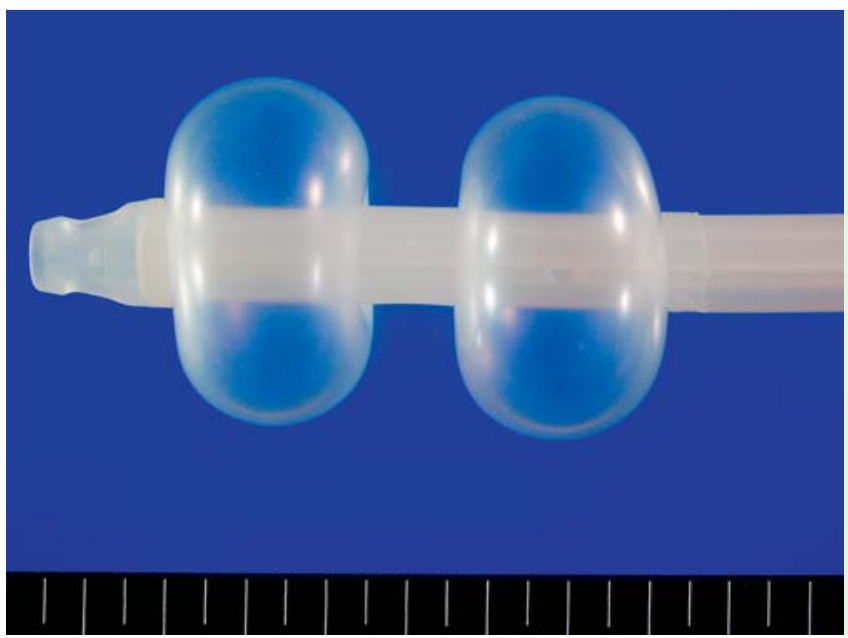

Fig. 1 The tip of the double-balloon rectal catheter showing the two inflated balloons.

Endoscopic mucosal resection (EMR) is a standard treatment for intramucosal colorectal neoplasms. Bleeding is one of the common complications of EMR $[1,2]$. Bleeding is often stopped using hemoclips [3], soft coagulation with hemostatic forceps [4], and hypertonic saline-epinephrine injection [5], but it may be difficult to locate the bleeding vessel if the bleeding is continuous or massive.

The Y-tube double-balloon rectal catheter (Create Medic, Yokohama, Japan; Fig. 1) is designed for use during barium enema examinations. The catheter is approximately $40 \mathrm{~cm}$ in length and has two separate balloons at the tip.

We report three cases of effective hemostasis using a barium enema balloon catheter for uncontrolled bleeding during EMR of large rectal polyps. All lesions were located in the lower part of the rectum, adjacent to the anal verge. The lesions were $20 \mathrm{~mm}, 30 \mathrm{~mm}$, and $50 \mathrm{~mm}$ in diameter. One of the three lesions was endoscopically removed en bloc ( $\bullet$ Fig. 2a) and two were removed by piecemeal EMR. Bleeding occurred immediately after the removal of each lesion ( Fig. $\mathbf{2 b}$ ). In each case, hemostatic forceps could not be used as the bleeding vessel could not be detected because of the massive bleeding.

The double-balloon catheter was therefore used to compress the vessel and control the bleeding. The catheter was inserted via the anus into the rectum, and the balloon was inflated with up to $40 \mathrm{~mL}$ of air. The balloon was deflated and the catheter was removed after 5-15 minutes, with the scope then being re-inserted to examine whether or not the bleeding had stopped ( Fig. 2c). If the bleeding had not stopped, a second period of balloon compression was applied.

When visibility is poor and detection of the bleeding vessel is obscured as a result of continuous or massive bleeding in the rectal region, hemostasis with a balloon catheter is an effective and expedient treatment method.

\section{Endoscopy_UCTN_Code_CPL_1AJ_2AZ}

Competing interests: None

\section{N. Matsui ${ }^{1}$, X. Bai ${ }^{1}$, D. Yoshimura ${ }^{2}$, M. Sugi ${ }^{1}$, A. Nakasha ${ }^{1}$, A. Kuwano ${ }^{1}$, Y. Shimokawa ${ }^{1}$, K. Oogoshi ${ }^{1}$, M. Tanaka ${ }^{1}$, K. Nakamura ${ }^{3}$}

${ }^{1}$ Department of Gastroenterology and Hepatology, National Hospital Organization Fukuoka Higashi Medical Center, Koga, Japan

2 Department of Gastroenterology, Saiseikai Fukuoka General Hospital, Fukuoka, Japan

${ }^{3}$ Department of Medicine and Bioregulatory Science, Graduate School of Medical Sciences, Kyushu University, Fukuoka, Japan
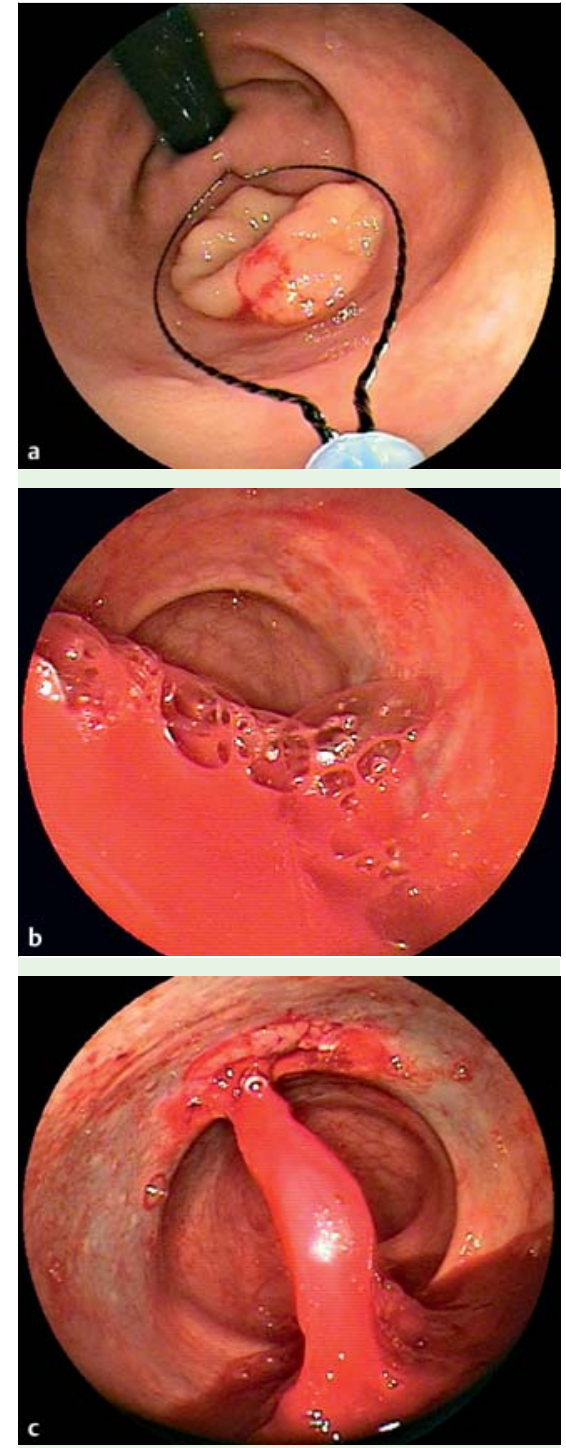

Fig.2 Endoscopic appearances in a patient undergoing endoscopic mucosal resection (EMR) for a large rectal polyp showing: a the 3-cm diameter, flat rectal lesion; $\mathbf{b}$ massive and continuous bleeding after EMR, which made location of the bleeding vessel difficult; c markedly reduced bleeding after 5 minutes of compression, which allowed the bleeding vessel to be identified so that a hemostatic clip could be deployed to eliminate the bleeding completely. 


\section{References}

1 Heldwein $W$, Dollhopf $M$, Rösch $T$ et al. The Munich Polypectomy Study (MUPS): prospective analysis of complications and risk factors in 4000 colonic snare polypectomies. Endoscopy 2005; 37: 1116-1122

2 Oka S, Tanaka S, Kanao H et al. Current status in the occurrence of postoperative bleeding, perforation and residual/local recurrence during colonoscopic treatment in Japan. Dig Endosc 2010; 22: 376-380

3 Binmoeller KF, Thonke F, Soehendra N. Endoscopic hemoclip treatment for gastrointestinal bleeding. Endoscopy 1993; 25: 167 - 170
4 Nagata S, Kimura S, Oogoshi $H$ et al. Endoscopic hemostasis of gastric ulcer bleeding by hemostatic forceps coagulation. Dig Endosc 2010; 22: $22-S 25$

5 Matsui N, Sugi M, Bai X et al. Effective hemostasis with hypertonic saline-epinephrine solution for uncontrolled bleeding during endoscopic submucosal dissection of the stomach. Dig Endosc 2012; 24: 476

\section{Bibliography}

Dol http://dx.doi.org/

10.1055/s-0032-1326282

Endoscopy 2013; 45: E122-E123

(c) Georg Thieme Verlag KG

Stuttgart · New York

ISSN 0013-726X

\section{Corresponding author}

N. Matsui, MD, PhD

Department of Gastroenterology and Hepatology National Hospital Organization Fukuoka Higashi

Medical Center

Chidori 1-1-1

Koga 811-3195

Japan

Fax: +81-92-9438775

normatsui@yahoo.co.jp 